\title{
GESTÃO DE ÁGUAS: UM DESAFIO GEO-INSTITUCIONAL ${ }^{1}$
}

\section{Water management: a geo-institutional challenge}

\author{
Gisela A. Pires do Rio \\ Prof $^{\mathrm{a}}$ Titular do Depto. de Geografia da UFRJ \\ giselario43@hotmail.com
}

Artigo recebido em 12/06/2017 e aceito para publicação em 22/06/2017

DOI: $10.12957 /$ tamoios.2017.29156

\begin{abstract}
Resumo
O presente artigo discute, à luz dos aportes da perspectiva institucionalista aplicada à geografia, as interações entre regulação e território a partir da análise da gestão da água no Brasil. Ao longo do texto emergem noções como dominialidade, patrimônio e conflito federativo que mostram o quanto a complexidade das malhas de gestão não permite a redução a uma unidade espacial imutável. Ou ainda ao considerarmos as redes de infraestrutura, aspectos relevantes puderam ser evidenciados, tais como: a interdependência e a lógica de redistribuição e acessos a recursos essenciais como a água. Deste modo, confrontando-se as redes técnicas às malhas de gestão, observou-se que a noção de superfícies de regulação é conceitualmente adequada para apreender as questões relativas ao acesso aos recursos, em particular a água. Por fim, a partir de dois exemplos, a licitação para a prática da aquicultura no lago do reservatório da hidroelétrica de Itaipu na fronteira entre Brasil e Paraguai e a transposição das águas do Paraíba do Sul para o rio Guandu no Estado do Rio de Janeiro, ilustrou-se a diversidade de situações em termos de acesso à água, indicando a complexidade e imbricação territorial que propiciam os sistemas regulatórios.
\end{abstract}

Palavra-Chave: Gestão da Água, Superfície de Regulação, Território, Regulação.

\begin{abstract}
This article, using the contributions of the institutionalist perspective applied to geography, analyzes the interactions between regulation and territory in the case of water management in Brazil. Using two examples, the bidding for the practice of aquaculture in the reservoir lake of the Itaipu hydroelectric plant in the border of Brazil and Paraguay and the waters transposition of Paraíba do Sul River to the Guandu River in the State of Rio de Janeiro, this paper illustrated the diversity of situations in terms of access to water, indicating the complexity and territorial imbrication that provide the regulatory systems. Thus, in the comparison of technical and management networks, it was observed that the notion of regulatory surfaces is conceptually adequate to analyze the issues related to access to resources, especially water.
\end{abstract}

Keywords: Water Management, Regulation Surface, Territory, Regulation. 


\section{INTRODUÇÃO}

As questões relativas ao espaço econômico e à organização do espaço geográfico, com possível identificação e reconhecimento do papel dos dispositivos regulatórios na dinâmica territorializada de atividades econômicas e dos serviços concedidos, adquiriram importância crescente ao longo das duas últimas décadas. Em parte, porque são tributárias do interesse e reconhecimento do papel das instituições no processo de desenvolvimento econômico de regiões, integram o conjunto de infraestruturas que incidem no sistema produtivo e porque refletem as mudanças do papel do Estado frente aos serviços e atividades que lhe eram atribuídos como atuação específica. Em termos gerais, essas transformações impuseram adaptações significativas tanto para os diferentes setores da economia como para os mais distintos territórios.

As crises estruturais caracterizam mudanças e rupturas nas regularidades e coerência das instituições (BOYER, 1995). A presença de instituições enraizadas no território complementa e tensiona o processo de globalização impulsionado por organizações de toda natureza (SASSEN, 2006), que fragmentam e desverticalizam a produção, a fim de melhor explorar os recursos naturais e os serviços em rede; ambos foram objeto de desregulamentação nos anos 1990. Esta situação reveste-se de particular interesse, especialmente quando consideramos as transformações que vêm ocorrendo nos serviços públicos concedidos. Nos últimos vinte anos, essas mudanças alteraram as formas tradicionais de gestão e impuseram desafios consideráveis à introdução de novos arranjos institucionais. Nem sempre o conjunto de infraestrutura foi exclusivamente considerado atribuição do Estado. O exemplo do Brasil é bastante ilustrativo, quando consideramos a evolução dos sistemas energéticos e de telecomunicações. A partir da década de 1990, porém, intensificaram-se as pressões para a reabertura desses setores ao capital privado.

Há evidentemente uma multiplicidade de fatores, com destaque para aqueles de ordem social, política e econômica, que explicam a configuração institucional e sua transformação ao longo do tempo. É importante lembrar que a maioria das instituições, senão todas, são originárias de contingências e coalizões sociais, políticas e econômicas e que, por isso mesmo, requerem um marco regulatório para sua própria evolução e transformação e como dispositivo frente aos processos multilocalizados $\mathrm{e}$ transfronteiriços, próprios à globalização (SASSEN, op. cit).

$\mathrm{Na}$ geografia econômica, as mudanças impostas pelo processo de globalização trouxeram para este campo a preocupação com a dimensão institucional e sua relação com a regulação das atividades econômicas (SCOTT, 1995; STORPER, 1997; AMIN, 2000; WOOD; VALLER, 2001, AMIN, 2000, AMIN; THRIFT, 1994; GERTLER, 2004; MARTIN, 1996; HUDSON, 2005, PECK, 2000; BENKO, 1996, etc.). A emergência de uma abordagem que considera ambiente institucional (NORTH, 1990; AMIN, 2000) e densidade institucional (AMIN; THRIFT, 1994) como elementos importantes nas relações entre agentes econômicos e território refletiu-se na ampliação da base conceitual em geografia econômica, principalmente no que diz respeito às interdependências não mercantis, relacionadas às formas como distritos industriais californianos, meios inovadores, sistemas produtivos locais e clusters de inovação. Essas interdependências englobam, além do conjunto de normas formais, as regras e convenções informais, conhecimento tácito e o conjunto de estruturas não hierárquicas que conferem especificidade tanto às regiões como às organizações.

Há uma questão subjacente que é a da adequação possível entre os territórios herdados e os territórios que são delimitados por marcos regulatórios específicos. Estes últimos, de reconhecimento mais imediato, são as unidades de conservação, os espaços 
de circulação e aqueles demarcados para permitir o acesso a recursos naturais tanto em terra, como em mar. São, portanto, fronteiras econômicas e de investimento que se abrem e requerem articulação/desarticulação dos dispositivos regulatórios nos diferentes países. Este aspecto é igualmente uma questão subjacente à gestão de águas na medida em que aproxima os elementos relativos à disponibilidade de água, à segurança hídrica, geração de energia elétrica, irrigação e dos serviços de água e esgoto ${ }^{2}$.

A exploração de recursos hídricos e a distribuição de água exigem uma organização institucional complexa apoiada em um sistema de concessões, contratos, controle sobre as fontes, vazões e disponibilidade, acesso, cobertura e tarifas dos serviços concedidos. Este sistema apresenta, portanto, organização espacial complexa pela combinação de malha e rede, que envolve um número crescente de agentes econômicos e atores sociais, colocando desafios significativos para a regulação da exploração de recursos naturais e dos serviços que lhes são associados. Duas formas espaciais predominam: as superfícies, notadamente associadas à distribuição geográfica dos estoques; e a rede que assegura conexão entre áreas de produção/exploração e áreas de consumo, que exigem redes de transmissão/transferência e distribuição, configurando-se, portanto, espaço de fluxos.

\section{AS MALHAS DA GESTÃO E AS REDES DE INFRAESTRUTURA}

Há relativamente poucos estudos que consideram de modo explícito a regulação de atividades de produção, distribuição e circulação de recursos naturais de uma perspectiva geográfica. Contraditoriamente, a problemática das redes técnicas e sua relação com o território, seja como elemento de coesão, seja como elemento de contestação de malhas de gestão (OFFNER; PUMAIN, 1996; DUPUY, 1991) ou como nova espacialidade foi bastante analisado.

De um modo geral, é possível notar certo distanciamento sobre as diferentes construções territoriais que intervêm na regulação do acesso ao mais fundamental dos recursos para a reprodução de toda sociedade: água. Além da tomada e distribuição de terras, o traçado de limites e as demarcações imprimem uma malha para apropriação de outros recursos como, por exemplo, os florestais e minerais e, sobretudo, do controle da água. São essas malhas e linhas que materializam territórios políticos, propriedades privadas e zonas econômicas exclusivas como expressão de territorialidade (SACK, 1986), poder e cultura. Claramente percebidas na separação entre áreas de agropecuária e florestas, as demarcações são igualmente objeto de disputas nos espaços marítimos ${ }^{3}$, sobretudo em situações de mudanças institucionais, como aquela que originou os modelos de concessão para exploração de petróleo em águas profundas, ou como a projeção dos direitos territoriais de Estados que incidem na exploração do subsolo marinho, como as disputas entre Estados localizados no entorno do Mar Cáspio, ou sobre o controle de áreas pesqueiras como as tensões entre Peru e Equador.

As malhas, segundo Lévy e Lussault (2003), podem ser consideradas realidades empíricas ou modos de representação para o estudo do espaço geográfico. As malhas se impõem na composição administrativa que cobre o território, e também na regulação dos espaços marítimos para as diferentes formas de utilização: exploração de recursos pesqueiros, minerais, rotas de circulação, implantação de cabos de fibra ótica, demarcação do mar territorial, zona econômica exclusiva, etc. Sua importância é enorme, sobretudo em casos de rupturas institucionais radicais. Exemplificando, o desmantelamento da União Soviética fez emergir no mar Cáspio tensões e disputas sobre a demarcação das águas territoriais dos países situados no seu entorno. 
As malhas constituem, em ambos os sentidos, a estrutura administrativa e jurídica que projetada no espaço fundamenta a gestão do território; são linhas que impõem limites, redefinem horizontes de investimento e de exploração de recursos e delimitam espaços de circulação. Malha viária, aeroviária, urbana, malha municipal ou estadual são exemplos de realidades empíricas, jurídicas e políticas, que não se restringem a sítios específicos nem apresentam as propriedades intrínsecas às redes de infraestrutura. Ao contrário, as redes definem a distância topológica de modo binário, alterando a conectividade e a acessibilidade dos lugares, permitindo aos usuários acesso aos serviços de modo imediato e instantâneo (DUPUY, 1991). Como estrutura de gestão e de apropriação, as malhas podem ser fixas independentemente da evolução ou do desenho das redes.

As malhas expressam, pois, certa rigidez, estabilidade e permanência de limites, contraponto às instabilidades ou indeterminações que podem ser geradas pelas redes. Esta é em certo sentido a compreensão de Raffestin (1980) para quem as malhas constituem divisões e limites que possibilitam o exercício do poder, isto é, as malhas definem limites em uma perspectiva relacional que engloba atores, instituições, organizações e estratégias. A ênfase na manifestação de toda comunicação como fundamento da relação social nos permite, em nossa discussão, diferenciar as malhas de gestão das redes de infraestrutura. Assim, reservamos a noção malha de gestão para indicar espaços de exercício de algum tipo de poder e de negociação, o que pressupõe, por conseguinte, considerar tensões, conflitos e disputas em torno de projetos individuais e coletivos. As redes de infraestrutura são objetos que atravessam essa malha, demandam regulação específica e, que por isso mesmo, podem exigir novas práticas de gestão do território.

A evolução das redes de infraestrutura ${ }^{4}$ encontra um paralelo com o crescimento e expansão das cidades. As restrições técnicas fizeram com que tanto as redes de iluminação pública, energia elétrica, gás, água e esgoto fossem, inicialmente, limitadas às cidades, tornando-se condição do urbano (DUPUY, 1991; OFFNER; PUMAIN, 1996). Neste sentido, não haveria uma clivagem nítida entre as redes e a cidade. Essas redes não são apenas aparatos técnicos mais ou menos eficientes; elas constituiriam um dado importante da organização da cidade. Esta infraestrutura que assegura a coesão e solidariedade, revela também oposição e confronto em relação às malhas administrativas (OFFNER ; PUMAIN, op.cit.). Quanto de água colocar à disposição da população e de onde retirar a água para abastecê-la foram problemas que exigiram, ao mesmo tempo, políticas e práticas específicas de intervenção e uma matriz institucional que as acompanhassem. À esta estrutura correspondeu uma organização monopólica. O monopólio sobre a rede significa controle no acesso ao recurso e no estoque de usuários que estão conectados à rede, condição necessária para obter o serviço (PIRES DO RIO; SALES, 2006).

Esta evolução, identificada como "revolução hidráulica" (LACOSTE, 2001b) envolveu, desde o início, um sistema de captação, transporte, tratamento e distribuição e alterou o próprio sentido dos serviços públicos. As redes de infraestrutura, principalmente as redes de eletricidade, de gás e de água estavam, na origem, condicionadas à escala urbana. Os problemas de estabilidade no serviço, as dificuldades de relação entre os atores responsáveis pelos serviços, práticas cotidianas e política local impuseram a constituição de um regime de monopólio que configurou a organização dos diferentes serviços. Para alguns autores a urbanização está de tal modo intrinsecamente associada à organização, controle e domínio dos fluxos de água corrente, que torna a cidade um objeto [de gestão] híbrido (SWYNGEDOUW, 2001), não sendo mais possível distinguir o natural do artificial. 
O desenvolvimento das redes técnicas tem, no entanto, implicações importantes para a organização do espaço para além da cidade e permitem a emergência de novas economias territoriais. Desde o início, a ampliação dessas redes de infraestrutura implicou igualmente na constituição de empresas com estratégias em escala industrial ${ }^{5}$. A importância desse sistema que evoluiu das fontes dispersas pela cidade às redes de captação e distribuição, confrontou-se desde o início à situação de bem coletivo: não exclusividade e não rivalidade ${ }^{6}$. Não por acaso, no século XIX, as primeiras companhias que exploravam os serviços públicos foram constituídas como companhias de água e iluminação, tal como a Lyonnaise des Eaux (atual Suez) (LACOSTE, 2001a). Se inicialmente a expansão das redes estava associada à capacidade das empresas em implementá-las, elas definiram em grande medida o acesso aos recursos hídricos, isto é, em sentido mais amplo, definiram as condições de acesso ao recurso e simultaneamente a um serviço público.

Os interesses dos agentes que prestam o serviço têm expressões territoriais diversas e não se confinam a um espaço que lhes é pré-existente, embora se desenvolvam a partir de uma estrutura inicial ${ }^{7}$, principalmente nas cidades. Independentemente da relação com a expansão da cidade, o exercício do monopólio foi possível em diferentes escalas: no nível nacional, sobre a rede de transmissão de energia elétrica e de telefonia, no nível regional e local sobre a rede de distribuição e nos serviços de água e esgoto e coleta e tratamento de lixo (PIRES DO RIO; SALES, 2006). Retoma-se trabalho anterior (PIRES DO RIO; SALES, op.cit.) para lembrar que toda rede de infraestrutura possui elevada irreversibilidade, sua extensão e conectividade qualificam os espaços e criam diferenciações significativas entre cidades e entre bairros de uma mesma cidade. Como essas redes podem interferir na malha da gestão do território e criar desafios institucionais é uma questão que nos parece importante para se compreender as interdependências entre a dinâmica de espaços econômicos e a evolução das instituições, pois se as redes permitem conexão, deslocamento e fluxos implicam, no plano teórico, na articulação solidária dos espaços.

Uma das características essenciais das redes de infraestrutura diz respeito à relação direta entre a dimensão da rede de distribuição e densidade de ocupação das áreas a serem abastecidas: as soluções de engenharia permitem controlar os recursos que estão situados a distâncias cada vez maiores dos centros de consumo, criando um sistema de dutos e linhas para transporte e transmissão de água, de energia elétrica e de combustíveis. Como serviço concedido, grande parte da rede de distribuição é confinada à escala da cidade, enquanto o aprovisionamento abrange uma escala mais ampla em função das distâncias entre a localização de fontes e mananciais e as áreas consumidoras. As redes técnicas permitem, assim, evidenciar tanto a importância relativa dos lugares como a escala geográfica na qual a organização do abastecimento se efetua (OFFNER; PUMAIN, 1996; MUSSO; CROZET; JOIGNAUX, 2002). Constituem, portanto, superfícies de regulação. A extensão e o nível de investimentos estão longe de atingir o ideal de universalização, mesmo nas cidades onde as redes cobrem grande parte da área urbana como no Rio de Janeiro ou São Paulo.

Se as redes de infraestrutura estão associadas ao crescimento das cidades, a necessidade de abastecimento demanda a captação em fontes situadas a distâncias cada vez maiores, abrangendo áreas mais amplas que os limites da cidade ou das unidades administrativas. Não há, nesse sentido, uma gestão direta pelas companhias que atuam exclusivamente na esfera municipal. As redes de infraestrutura que envolvem captação, adução, tratamento e distribuição requerem regulação específica para assegurar a gestão da água, apresentando, nesta escala, um duplo processo de integração vertical e horizontal. A separação gerencial da rede arterial e da rede capilar (SILVA, 2003) tem 
em vista dificultar as práticas de captura do agente regulador por parte dos agentes privados, de grupos políticos constituídos nos ministérios respectivos ou ainda de grupos de interesse regional que se apropriam de setores de infraestrutura, e pelo crescimento da participação de multiutilities $^{8}$ na disputa por concessões de serviços públicos.

Não obstante a separação entre rede arterial e capilar, uma parte significativa dos conflitos de ordem regulatória que ocorrem nos serviços em rede incidem sobre a classificação desses segmentos, que correspondem às atividades de transporte e distribuição. Alguns dessas disputas traduzem-se por conflitos federativos. A questão da regulação sobre os serviços implica na separação do segmento da rede, que será regulado pela agência nacional, e aquele que será regulado pelas respectivas agências estaduais. A situação do gás natural ilustra bem esse aspecto. Aos estados compete a regulação da rede de distribuição a partir das estações de transferências ${ }^{9}$ para distribuição nas cidades. Todavia, a possibilidade de transferência interna entre estabelecimentos de uma mesma empresa foge ao controle da regulação estadual, isto é, uma empresa que tenha o monopólio sobre a rede de dutos para transporte do gás e que ao mesmo tempo detenha uma unidade para o seu processamento, pode levar o gás até essa unidade sem fazer uso da rede de distribuição. A entrada de novos atores que obtêm concessões para exploração e produção de gás pode igualmente suscitar novas questões de ordem federativa contrapondo, de um lado, as companhias estaduais de serviços públicos e agências estaduais de regulação e, de outro, união e companhias multiutilities.

A força das infraestruturas em rede reside antes de tudo em suas características intrínsecas. Uma rede é essencialmente uma estrutura de diferenciação dos lugares, podendo conferir-lhes uma posição estratégica mais ou menos duradoura, um modo de organização do espaço que privilegia a circulação sincrônica de produtos, pessoas e informação (DUPUY, 1991). O espaço tecnicamente organizado por essas redes implica, porém, em descontinuidades que se opõem aos espaços bem demarcados que caracterizam as regiões ou os territórios. As redes permitem que nos indaguemos sobre a tensão entre continuidades e descontinuidades. Mais objetivamente, as redes, pelas trocas e principalmente pelos serviços que lhes são associados, constituem espaços regulados. São nesses espaços que prevalecem normas que, mesmo implícitas, definem as condições de acessibilidade. As redes e as interações que por elas são viabilizadas pressionam pela adoção de compromissos negociados entre os agentes (PIRES DO RIO, 2006), ou, como já antecipado por Offner e Pumain (1996), se interessar pelas redes técnicas e pelo jogo de atores é compreender que as questões ligadas a estas redes não são exclusivamente técnicas, mas também institucionais, econômicas e políticas.

A regulação dos serviços implica, no entanto, em certo remanejamento das hierarquias espaciais e de certa capacidade de articulação e negociação ou, em outros termos, na constituição de compromissos institucionais como condição necessária para o funcionamento de tais estruturas e como fundamento da coesão institucional. A regulação pressupõe as seguintes orientações: a) coordenação no atendimento das demandas pelos serviços que são desigualmente ofertados; b) conexão entre redes operadas por agentes concorrentes a fim de evitar a constituição de monopólios regionais ${ }^{10}$ que acabam por dificultar o acesso aos serviços; e c) controle sobre as empresas verticalmente integradas que tendem a separar as atividades de captação e distribuição e concentrar-se em áreas mais densas sem, contudo, deixarem de operar nesse sistema.

Esses elementos obrigam-nos a reconsiderar certas características da regulação como exclusivamente os atos de apropriação, nomeação e ordenamento como 
atribuições da esfera pública, que asseguraram domínio e posse de territórios conquistados, predominante até o final século XIX. A coordenação entre as áreas que são ligadas por uma mesma rede propicia a emergência de novas institucionalidades, como por exemplo, no caso da exploração de petróleo ou no uso compartilhado de recursos hídricos. Se considerarmos os efeitos da abertura do setor de petróleo e a malha hídrica construída para atender demandas urbanas concentradas, percebemos a multiplicidade de atores que são passíveis de integrar a esfera das decisões e negociações. Contudo, em determinadas situações, a capacidade de algumas organizações em operar redes de infraestrutura e de distribuição vem permitindo a realização de estratégias de diversificação horizontal através das quais as empresas tendem a atuar em vários setores de infraestrutura.

\section{MUDANÇAS INSTITUCIONAIS E REGULAÇÃO}

No caso brasileiro, as mudanças e alterações na matriz institucional na década de 1990 levaram à cessão de bens do patrimônio público ao setor privado que vem exigindo constantes adaptações no quadro regulador dos diferentes serviços concedidos e da exploração de recursos naturais.

A reformulação do papel do Estado e os ajustes institucionais se expressaram, dentre outras medidas, na criação das Agências Reguladoras, como a Agência Nacional de Energia Elétrica (ANEEL), Agência Nacional de Transportes (ANT), Agência Nacional de Petróleo (ANP) e Agência Nacional de Águas (ANA). Por um lado, o espaço de atuação das agências corresponde à jurisdição territorial do Estado. À cada uma das agências corresponde um determinado setor de atividade econômica ou serviço público concedido.

A adoção de um modelo de regulação multissetorial representa sempre um ponto delicado no processo de tomada de decisão. A divisão de competências entre as diferentes agências consiste em desafio significativo. No caso das atividades petrolíferas, a Emenda Constitucional $n^{\circ}$ 09/1995 alterou profundamente a função exercida pelo Estado brasileiro. Até então, elas eram desempenhadas pelo Estado por sua conta e risco, em regime de monopólio, sendo vedada, por disposição constitucional (art. 177 da CF/1988) a inserção de novos agentes nessas atividades.

Os ajustes e alterações estão associados à dinâmica espaço-temporal, sujeitos à condições de investimento e fatos que podem pressionar por modificações daquele quadro. Podemos citar como exemplo as modificações do quadro regulador do petróleo e gás a partir das descobertas do pré-sal, em 2010, que impuseram modificações na regulação: regime de partilha de produção em substituição ao regime de concessão dos direitos de exploração das reservas, criação de empresa pública para gerir os novos contratos e criação de um fundo de investimentos pra concentrar recursos financeiros oriundos das atividades de prospecção, exploração, produção e comercialização do petróleo.

No que diz respeito aos recursos hídricos é preciso distinguir o marco que regula a gestão destes recursos e aquele que regula a concessão dos serviços de água e esgoto, ao qual corresponde a divisão de atribuição entre os entes da Federação. A atribuição dos serviços de água e esgoto aos municípios representa uma lógica diferente da gestão de recursos hídricos, porque os primeiros são necessariamente dependentes da rede de infraestrutura.

Nas primeiras implantações, os serviços de água e esgoto estiveram associados à ideia de concorrência, definindo-se áreas para a concessão do serviço para as companhias interessadas, característica semelhante, aliás, aos demais serviços 
concedidos que têm na rede o princípio da atividade. Nas regiões ou nos locais onde havia reduzido grau de conexão entre as redes de abastecimento e de captação de diferentes companhias prestadoras de serviços, a formação de monopólios regionais foi favorecida. Uma das consequências desta situação é a concentração a partir do controle de redes de abastecimento e que teve seu fundamento no argumento da eficiência econômica contida no regime de monopólio natural.

Por outro lado, a gestão de águas envolve igualmente questões de dominialidade dos corpos hídricos. Há uma complexa massa de normas e leis associadas ao entendimento de dominialidade com repercussões no próprio marco regulatório. A rigor, a Constituição de 1988 define, em seu artigo 20, a dominialidade da União sobre "os lagos, rios, e quaisquer correntes de água em terrenos de seu domínio, ou que banhem mais de um estado, sirvam de limites, ou se estendam a territórios estrangeiros ou deles provenham, bem como os terrenos marginais e as praias fluviais", enquanto o domínio dos estados é definido sobre as "águas superficiais e subterrâneas, fluentes, emergentes e em depósito, ressalvadas nesse caso, na forma da lei, as decorrentes de obras da União" (Artigo 26).

Como parte do aparato institucional, o marco regulador para o gerenciamento dos recursos hídricos, a Lei 9433, estabelece a bacia hidrográfica como unidade espacial de planejamento. No entanto, em bacias interestaduais há corpos líquidos de domínios da União e dos estados. Em nosso entendimento, essa questão vai além da atribuição de competência e esfera de intervenção dos estados e da União. Ela expressa, em sua essência, a naturalização de um espaço para controle do recurso. Esse controle não será, como já foi anteriormente mencionado, de forma direta; ele será necessariamente operado por meio de concessões. Os problemas que daí decorre são bastante conhecidos: instrumentalização ${ }^{11}$ desses espaços, aumento de riscos de bloqueio por parte daqueles que controlam os nós de rede e risco de captura do regulador pelos agentes regulados. As malhas de gestão são, assim, mais amplas e extensas que as redes de infraestrutura e bastante distintas dos espaços naturais.

Esta questão não é simples. A relação entre dominialidade- regulação- gestão abre um campo enorme para a definição de territórios estruturados por redes de infraestrutura em diferentes escalas e ainda aqueles que estão sendo constituídos por meio de concessões para exploração dos corpos de água ou de outros recursos minerais neles localizados. A peculiaridade das redes é que elas podem reconfigurar o território ao mesmo tempo em que são suporte para um grande número de atividades.

\section{OS APORTES DA PERSPECTIVA INSTITUCIONAL}

Os trabalhos de Geografia Econômica relacionados à perspectiva institucional (SCOTT, 1995; STORPER,1997; JESSOP, 1995; PECK, 2000, CLARK et al, 2000, AMIN, 2000, entre outros) assumem, em geral, que as atividades econômicas são social e institucionalmente constituídas (MARTIN, 2000), similarmente às premissas adotadas por economistas como North (1990) e Knight (1992). Ou seja, o conjunto de atividades econômicas requer normas e dispositivos de regulação econômica e social nos processos de produção, troca, consumo e transporte que podem variar entre as diferentes formas de organização social e política e produzir, em sua evolução, novas institucionalidades.

Dentre as muitas definições do termo instituição, a perspectiva institucionalista tende a assumir que as instituições envolvem todo o conjunto e arranjos que organizam e regulam a vida em sociedade e as relações sociedade-natureza. Knight (1992), cuja análise dos conflitos e contradições nas distintas sociedades assinalou a importância das instituições nos aspectos da vida em sociedade, desde as decisões econômicas e 
políticas até as interações entre indivíduos, e como fonte de transmissão de conhecimento e informação entre gerações. Sua análise reafirma que as instituições são regras que articulam e organizam a produção, distribuição e circulação dos meios materiais e as interações entre agentes, grupos e indivíduos em determinada sociedade. Neste sentido, as instituições são histórica e geograficamente determinadas: elas não são estáticas, isto é, mudam ao longo do tempo.

Buscando compreender como e porque as instituições se modificam, o porquê da estabilidade de instituições ao longo do tempo e dos efeitos diferentes de uma mesma instituição no desempenho econômico de determinadas sociedades, North (1990) chamou atenção para dois aspectos. O primeiro sobre o papel da matriz institucional no desenvolvimento econômico e o segundo sobre a dependência de trajetória constituída historicamente. Considerou dois tipos de instituições formais e informais. As formais surgiram como respostas para a resolução de conflitos entre agentes econômicos, e constituíram, no tempo, estruturas que influenciam na taxa, no modo e no regime de exploração de recursos naturais; as instituições informais são convenções produzidas pelas diferentes sociedades cujo respeito é vinculado aos valores socialmente instituídos. O segundo aspecto foi o da trajetória historicamente dependente da evolução e ritmo das mudanças institucionais. Decorre desta argumentação que há uma matriz institucional que fundamenta e legitima as divisões e ordenamento do território. Este fundamento não passa necessária e exclusivamente pela mediação do direito positivo, uma vez que as regras não formais promovem igualmente a redução de tensões e exercem papel importante na difusão de informações.

A diversidade de foco e a própria definição de instituição vêm permitindo a aplicação em estudos sobre a relação entre a localização geográfica e as aglomerações, a formação de instâncias especializadas com baixos custos de transação; o papel das localidades na formação de interdependências não mercantis e na natureza e evolução de regimes institucionais e seu papel na regulação social e governança local (MARTIN, 2000).

Parte desses trabalhos voltou-se para a discussão sobre interdependência entre a dinâmica de espaços econômicos e a evolução das instituições a partir das perspectivas abertas pelos trabalhos de Williamson (1985) e Aoki (1986), que colocaram em relevo os custos de transação em contexto de incerteza, isto é, um contexto marcado por intenso e veloz processo de incorporação de inovações tecnológicas por parte das firmas, obrigando-as a realizar mudanças nas formas de coordenação das atividades. Os custos de transação derivados da assimetria de informação entre firmas tenderiam a aumentar, donde o desenvolvimento de novas institucionalidades como forma de reduzir aqueles custos. Trata-se, portanto, de uma perspectiva na esfera da produção e na relação entre empresas. No sentido econômico do termo, governança implica na coordenação e formas de organização da firma frente às incertezas e falhas do mercado; significa, portanto, a coordenação de estruturas não hierárquicas na concepção e desenvolvimento das atividades da firma. É a partir desta construção que se desenvolveu a discussão sobre os distritos industriais segundo a vertente californiana (STORPER, 1997). Conceitualmente, diferencia-se instituição de organização. Esta última é a instância de organização de grupos ou indivíduos realização de uma função social.

Para Storper (1997) as instituições estão relacionadas ao conjunto de regras que condicionam o comportamento dos agentes e das atividades, aproximando-se de North (1991), que considera instituições como as regras do jogo em uma dada sociedade, estruturas criadas que regulam e limitam a interação das atividades humanas e que 
podem ser formais e informais. Em ambos encontramos a distinção entre instituições e organizações, assim como em Scott (1995).

Esta distinção é importante na medida em que um dos elementos intrínsecos às instituições diz respeito ao marco regulatório (SCOTT, 1995) que baliza tanto o comportamento individual como o funcionamento das atividades econômicas. Segundo o tipo de atividade, a regulação exercerá maior ou menor pressão sobre as organizações. Essa relação está no centro da regulação dos usos múltiplos da água e dos setores de serviços públicos concedidos. Cabe aqui um esclarecimento quanto a estes últimos. Constituem serviços públicos concedidos aqueles serviços que estão associados a uma função redistributiva e aos princípios de universalidade, não exclusividade e não rivalidade.

Assim, as regras e normas que regulam um sistema político e econômico podem tornar-se obstáculo e entrave quando novo modo de regulação se impõe, quer por destruição de determinado regime, quer impulsionado por reformas políticas e econômicas. Por outro lado, elas podem, por meio de possibilidades tecnológicas, viabilizar, por exemplo, a exploração de recursos localizados em espaços que se abrem como fronteiras inesperadas para a realização de investimentos como, por exemplo, o espaço marítimo, ou os setores intensivos em capital como os serviços públicos concedidos.

\section{GOVERNANÇA: UMA MEDIAÇÃO POSSÍVEL ?}

Se, no passado, a regulação confundia-se com as instituições, atualmente, a regulação restringe-se à atuação da esfera pública sobre o comportamento dos agentes econômicos, assegurando as condições de concorrência e de funcionamento dos serviços públicos concedidos. Este aspecto em nada diminui a importância e o reconhecimento dos dispositivos da regulação social fundadora das relações sociais e políticas. A questão crucial parece-nos, portanto, compreender a regulação como processo vinculado à organização das atividades econômicas nos territórios.

A argumentação central deste ponto de vista é a de que a dinâmica econômica permanece territorializada. A adoção da perspectiva institucional parte, assim, da análise da estrutura institucional para estabelecer o vínculo entre governança e gestão do território. Governança significa novas formas de ação pública caracterizadas por uma pluralidade de atores e organizações, implicando na articulação de normas de comportamento em relação a ação coletiva (AMIN, 2000). Ela atende às necessidades de explicar o estabelecimento de condições de regulação do comportamento dos agentes em diferentes territórios, isto é, o modo particular segundo o qual as diferentes institucionalidades se manifestam no espaço e interferem no desenvolvimento das regiões $^{12}$ (WOOD; VALLER, 2001). Estas são compreendidas como produto de relações passadas, remodeladas por múltiplas iniciativas tributárias das estratégias e ações de atores públicos e empresas que, ao desenvolverem suas respectivas estratégias, transformam este espaço (BENKO; LIPIETZ, 2000), mas encontram, igualmente, resistências que vão sendo estruturadas e reestruturadas em seu conteúdo.

A mediação entre regulação e território, por exemplo, pode ser compreendida como governança, para indicar o modo de estruturação e reestruturação dos vários espaços pelos agentes públicos e privados ou ainda a formação de arranjos participativos para a elaboração de políticas públicas (JACOBI, 2009). De modo bastante sintético e amplo, compreende-se governança como um tipo de regulação informal estabelecida para viabilizar a distribuição e controle de recursos compartilhados entre agentes e atores bastante diferenciados, seja em redes de 
organizações regionais, seja para a tomada de decisões sobre funcionamento de redes técnicas. A governança consiste em mecanismos para definição de estratégias comuns entre agentes cuja relação entre as atividades de cada um os torna interdependentes, por isso remete às estruturas em rede, aos efeitos de proximidade, às atmosferas e meios que facilitam o desenvolvimento dessas estratégias comuns. Em qualquer situação sua institucionalização é sempre complexa e contraditória (JACOBI, op. cit.).

Explica-se, assim, a importância do arranjo e da densidade institucionais atribuídas por Amin e Thrift (1994) na organização e desempenho econômico das diversas regiões. No entanto, Amin e Thrift (1994) não diferenciam claramente instituições e organizações. Ao definir a densidade institucional, referem-se a uma pletora de instituições como firmas, associações comerciais, agências de desenvolvimento, sindicatos, etc., caracterizando-se estes últimos como instâncias de organização para atuar como atores coletivos com algum peso na negociação de leis regimes de trabalho e produção.

Este conjunto de organizações- que os autores mencionados consideram como instituições- constitui um componente essencial da construção da densidade institucional que, por sua vez, requer não apenas a sua presença na região, mas igualmente o elevado grau de interação, uma estrutura bem definida de representação e entendimento coletivo sobre o envolvimento em um projeto comum para a região. A densidade institucional sofre restrições por sua imprecisão quanto ao modo efetivo que a faz emergir em alguns lugares e não em outros (MARTIN, 2000; CUMBERS et al, 2003), ou ainda quanto às condições que caracterizam aquilo que Thrift e Amin (1994) consideram como necessário: elevado nível de interação entre as instituições locais como forma de regular as relações sociais e os contratos entre agentes econômicos, perdendo de vista o que Jessop (2001) considera fundamental: o fato de que há uma seletividade espaço-temporal das instituições que envolve distintas modalidades por meio das quais as ações são produzidas.

A mediação pela noção de governança para indicar o modo de estruturação e reestruturação desses espaços pelos atores públicos que trabalham num "horizonte espacial" local ou regional pode não evidenciar os conflitos, oposições e coordenações inter-escalares que emergem nessas escalas (GILLY; PECQUEUR, 1995). Esta crítica apoia-se na própria fluidez da noção de governança que apresenta pelo menos três diferentes sentidos: a) coordenação de atividades no interior da empresa, governança corporativa, b) relações entre empresas e território, e c) como mecanismos para estratégia e ação comuns entre agentes que compartilham um mesmo recurso. Essas formas não podem ser, todavia, consideradas no mesmo nível. É importante distinguir aquelas definições que tratam de relações verticais e hierárquicas (empresas) das que se referem às estruturas horizontais de negociação (diferentes tipos de rede) e recursos compartilhados, os recursos hídricos.

Embora pareça contraditório, as redes podem, de algum modo, enfraquecer a capacidade de governança. A regulação/ des-regulação dos serviços públicos acentua, para Offner (2000), a perda de controle de algumas das organizações e agentes políticos, justamente pela maior complexidade política e diversidade de agentes públicos e privados que atuam nas diferentes escalas das redes de infraestrutura. Nunca é demais lembrar que as redes de infraestrutura podem tornar as divisões político-administrativas obsoletas (OFFNER, op. cit.), podem alterar o sentido da jurisdição territorial na qual estamos habituados analisar as políticas públicas, levando, a regulamentação/desregulamentação/re-regulamentação a substituir as políticas territorialmente circunscritas. 


\section{SUPERFÍCIES DE REGULAÇÃO: EXPRESSÃO TERRITORIAL DA GESTÃ̃O DE ÁGUAS}

A discussão até aqui realizada privilegiou a regulação em seu sentido amplo. Esta constituiu um elemento importante da ação do Estado Nacional: localizar, nomear, controlar e ordenar o espaço; foram ações que integraram o conjunto de decisões da esfera pública para assegurar domínio e posse de territórios conquistados, principalmente até o século XIX. Se, no passado, a regulação, confundia-se com as instituições, atualmente, a regulação restringe-se à atuação da esfera pública sobre o comportamento dos agentes econômicos assegurando as condições de concorrência, sobre o acesso, exploração e usos de recursos naturais e sobre os serviços públicos concedidos. Este aspecto em nada diminui a importância e o reconhecimento de uma regulação social fundadora das relações sociais e políticas.

O que merece atenção é que toda regulação, assim como as instituições, pode ser formal e informal. Enquanto as primeiras tendem a ser coercitivas, as segundas são voluntárias. Novamente indicamos que os mecanismos criados por sociedades milenares para a gestão de águas em várias regiões no mundo são importantes e em muitos casos informais. A questão crucial parece-nos, portanto, compreender a regulação como processo amplo, vinculado à organização das atividades econômicas inscritas no espaço, resultado da negociação de interesses sociais e políticos específicos e setoriais. Regulação engloba regulamentação, leis, contratos, controle de sua execução, e também as práticas e ações que governam relações informais. Não se pode antecipadamente estabelecer a orientação, direção e intensidade que o confronto de interesses opostos pode assumir, mas podemos imaginar.

A regulação de atividades produtivas e de serviços concedidos pode apresentar distintas modalidades: confundir-se com o território nacional; ou constituir um elemento de governança regionalmente centralizada/ descentralizada. Enquanto a primeira evoca o processo de regulamentação, desregulamentação e re-regulamentação que teve início na Inglaterra e nos Estados Unidos na década de 1980, espraiando-se, posteriormente para vários países, principalmente para a América do Sul, a segunda emerge do reconhecimento de que a manifestação de interesses requer convenções, normas e qualificações informais que balizam as divisões locais, as rivalidades regionais, a reduzida ausência de controle hierárquico e do papel das redes na articulação de territórios. Este ponto é relevante, pois a compreensão das atividades econômicas e sociais como redes e a regulação/ des-regulação das indústrias em rede ocorrem simultaneamente (OFFNER, 2000).

Essas duas modalidades não são de todo opostas. A primeira recupera a coordenação das atividades econômicas a partir da reestruturação decorrente da reforma do Estado e a ampliação do papel das agências de regulação. A segunda indica que novos marcos regulatórios estão sendo exigidos para permitir um certo tipo de alinhamento legal e operacional que viabilize o acesso a recursos naturais ou a mercados consumidores distintos daqueles circunscritos ao território nacional. Em ambas as situações, a necessidade de regulação para as atividades produtivas e de serviços é essencial. Há, neste sentido, uma interrogação sobre os dispositivos institucionais que regulam as relações econômicas, principalmente nas atividades que envolvem os serviços concedidos, a exploração de recursos naturais e estratégicos e o ambiente.

Esses aspectos projetam-se em espaços de soberania e espaços de disposição e utilização econômica (PERROUX, [1961]; 1994). É neste sentido que podemos compreender as superfícies de regulação ${ }^{13}$ como sendo caracterizadas por limites mais 
ou menos precisos em sua extensão. Derivam da necessidade de controle sobre determinadas frações do território, articulando espaços de soberania e espaços econômicos (ou a porção destes que se encontra em um determinado território nacional). A ideia superfície de regulação correspondendo aos espaços políticos com fronteiras bem delimitadas não pode ser considerada exclusiva no mundo atual ${ }^{14}$. Cabe notar que a regulação pública não é obrigada a circunscrever-se aos limites administrativos segundo a malha territorial que lhe dá suporte. Não se trata, neste caso, de eliminar o poder dos Estados, pois para serem constituídas, tais superfícies o são, até o presente, pela negociação entre espaços soberanos o que permite agilizar os fluxos econômicos, ou ainda criar espaços sujeitos a marcos multi-regulatórios, como nos mares e oceanos.

O conceito de superfície de regulação que viemos trabalhando desde 2000 (PIRES DO RIO; PEIXOTO, 2001; PIRES DO RIO; PEIXOTO; MOURA, 2001; PIRES DO RIO, 2006; 2008) permite definir determinada superfície a partir do objeto geográfico como, por exemplo, as redes de infraestrutura, ou a partir de projeções sobre o espaço geográfico, malhas de gestão, para criar condições objetivas de apropriação lá onde, a priori, não seria possível evidenciar os limites entre propriedades ou unidades de produção. As projeções paralelas e ortogonais que fornecem sustentação territorial para a apropriação e distribuição dos royalites do petróleo por estados e municípios, os lotes de pesca em lagos de represas e usinas hidroelétricas constituem o exemplo no segundo caso: são realidades empíricas que não apresentam as propriedades intrínsecas às redes de infraestrutura (PIRES DO RIO, 2008).

A superfície de regulação é compreendida como sendo uma superfície que tem como particularidade apoiar-se em malha específica que define, para os diferentes atores/agentes, as condições de acesso aos recursos que nela se concentram ou nos serviços que lhe são associados; constitui, portanto, configuração distinta e particular em termos de escala de gestão e de governança. Seu caráter operatório encontra-se, precisamente, na possibilidade de articular informações de natureza fixa e de fluxos em distintas malhas ( $C f$. Figura 1). Compreendida nestes termos, as superfícies são horizonte e limite e, por isso, as práticas de localizar, nomear, delimitar e ordenar o espaço delas necessitam como primeira medida de apropriação. 
Figura 1: Superfície de Regulação na Gestão de Recursos Hídricos

Superfície de Regulação na Gestão de Recursos Hídricos: Superposição de Limites

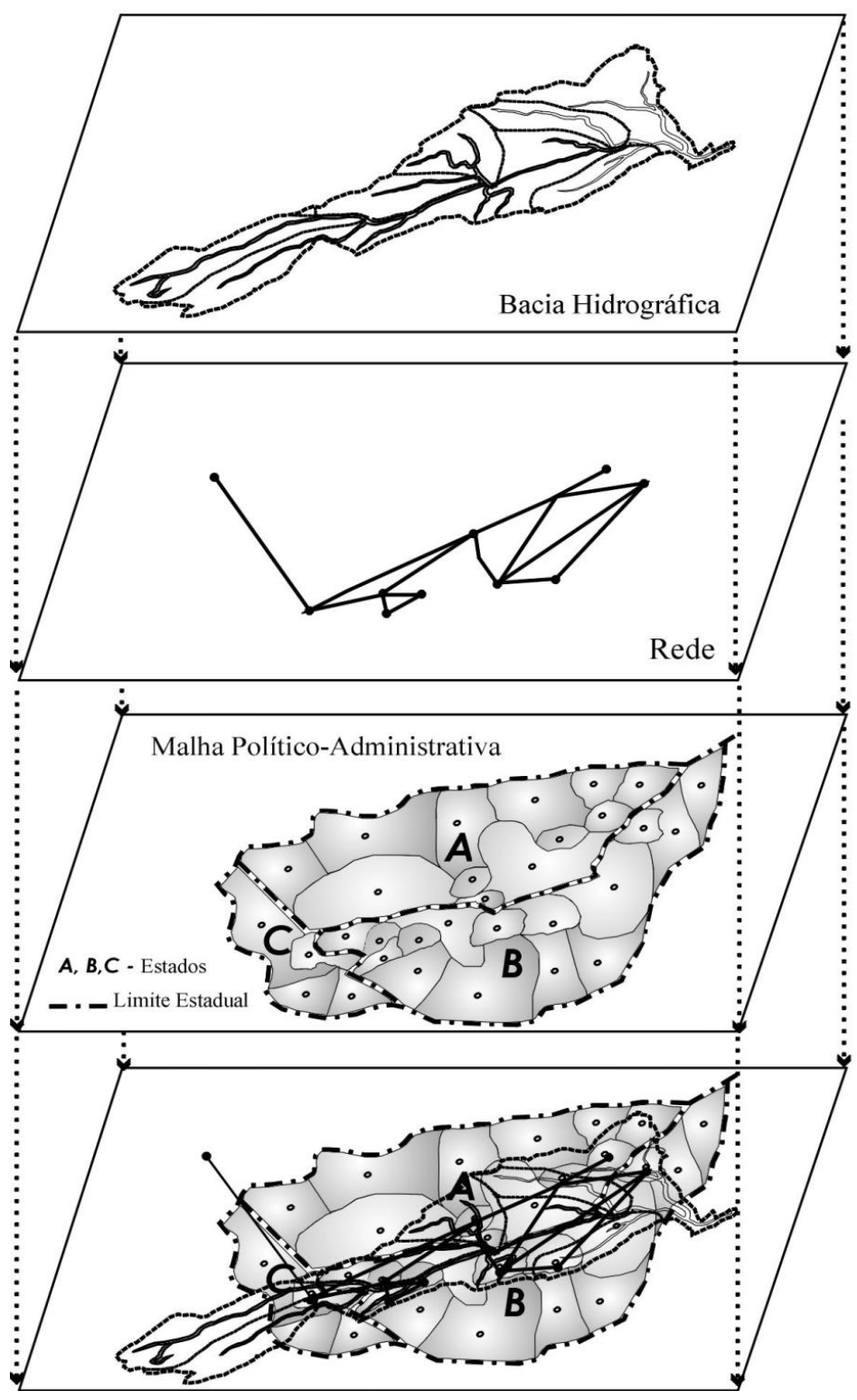

Essas superfícies emergem, assim, na formação e consolidação de um marco regulador para as atividades econômicas cuja estrutura pressupõe a existência de redes técnicas (eletricidade, telefonia, água e esgoto, petróleo e gás, transportes), na delimitação de espaços de preservação que integram o patrimônio natural ${ }^{15}$, na projeção $^{2}$ de malhas no espaço marinho que incidem na distribuição de royalties, na indicação de lotes para aquicultura, etc.

Dois exemplos ilustram os pontos até o momento abordados. Eles expõem as questões da dominialidade e da complexidade das malhas de gestão. Como foi anteriormente sugerido, a regulação pode atuar como incentivo ou coibição para o desenvolvimento de atividades econômicas. A cada momento, a malha pode ampliar-se ou reduzir-se, mas desafiam a habilidade das populações locais em participar efetivamente da gestão. A regulação dos serviços de água, mais do que qualquer outra 
regulação setorial, permite evidenciar as mais diferentes configurações de apropriação de um bem coletivo, tornado recurso.

A recente decisão de promover licitações para conceder direito de uso para aquicultura em áreas de reservatórios constitui um exemplo de novas superfícies de regulação que estão sendo criadas em espaços antes considerados de livre acesso. Neste caso, o uso das águas de domínio da União está sendo regulado por um conjunto de normas formulado pela Secretaria do Patrimônio da União (SPU), Ministério do Planejamento e Secretaria Especial de Aquicultura e Pesca da Presidência da República $(\text { SEAP })^{16}$

A primeira experiência que já está sendo realizada é a concessão de 155 lotes, de dois mil $\mathrm{m}^{2}$ no reservatório da hidrelétrica de Itaipu (http://jie.itaipu.gov.br/, acesso em dezembro de 2007). À diferença das demais concessões para prestação de serviços ou exploração de recursos naturais ${ }^{17}$ que oneram a concessão, a Secretaria Especial de Pesca e Aquicultura ${ }^{18}$ estabeleceu o regime de concessão não onerosa para a água de reservatórios de hidrelétricas ou de açudes. Os critérios para a cessão de direito ao uso do reservatório aplicam-se para aqueles que têm renda familiar de até 5 salários mínimos, residir no entorno do reservatório há três anos. Em contrapartida, os parques aquícolas e as áreas individuais, que serão explorados por empresas de grande porte e em escala industrial, serão submetidos ao regime de concessão onerosa ${ }^{19}$. Acrescenta-se a esses, os seguintes critérios para classificação: ser produtor rural atingido por barragem; ser assentado, filiado a associação, cooperativa ou colônia de pescadores com mais de dois anos de existência; ter participado de capacitação, curso ou treinamento em piscicultura; estar inserido em algum programa social; e ser aquicultor e pescador registrado (http://www.agenciabrasil.gov.br/noticias/2007/11/21, acesso em dezembro de 2007).

A regulação que começa a ser implementada ilustra vários pontos ${ }^{20}$. O primeiro consiste na ruptura de acesso para aqueles que não podem ser classificados como integrantes de uma associação ou cooperativa ou ter participado de um curso de capacitação promovido pela empresa Itaipu Binacional. A autonomia da população ribeirinha, que inclui população indígena, como, por exemplo, aquela que vive na Reserva Indígena Avá Guarani, é assim modulada pela regulação-gestão que incide sobre o reservatório. $\mathrm{O}$ segundo diz respeito à opção de uma política de geração de emprego e renda. Se a cessão não onerosa privilegia determinado grupo, esta é resultado de uma orientação de política pública com esta finalidade. Torna-se difícil, assim, a separação entre a regulação como instrumento de política pública daquela com objetivos estritamente setoriais que integram as atribuições das diferentes agências de regulação. O terceiro refere-se ao caráter internacional. Na margem paraguaia, a empresa dispõe de uma estação de aquicultura para a criação de alevinos, e já estende o programa de capacitação para pescadores e ribeirinhos no lado paraguaio. Não é possível identificar, neste plano, uma densidade institucional emergindo do local que possa influenciar na gestão. Neste nível de análise, a regulação deste tipo de uso está sob controle das instruções da empresa. Não é a bacia hidrográfica, não são os municípios, portanto, não é a malha federativa que articula e define as regras da gestão da água; diante do ator transfronteiriço-Itaipu- , é difícil separar coerção e adesão voluntária na gestão dos recursos compartilhados.

No caso do estado do Rio de Janeiro, a transposição, realizada na década de 1950 , das águas do Paraíba do Sul $\left(160 \mathrm{~m}^{3} / \mathrm{s}\right)$ para o rio Guandu, constitui um exemplo significativo para a discussão sobre a tensão entre malhas de gestão e as redes de infraestrutura para os serviços públicos e também entre público e privado. Essa transposição foi realizada para atender tanto ao Complexo Hidroelétrico de Lajes, da 
Ligth, como ao sistema integrado Guandu-Lajes-Acari $\left(49 \mathrm{~m}^{3} / \mathrm{s}\right)$ de abastecimento de água da CEDAE (Companhia de Água e Esgoto do Estado do Rio de Janeiro). Em outros termos, a vazão do rio Guandu é assegurada pela transposição de $2 / 3$ da vazão do Paraíba do Sul.

Sem entrar nos aspectos técnicos dessa obra, é importante lembrar seu significado para a região metropolitana do Rio de Janeiro (RMRJ): dessa transposição dependem cerca de $90 \%$ da população residente nos municípios que a integram. A população da RMRJ depende da qualidade da água que chega aos reservatórios do complexo de Lajes, das características técnicas empregadas nas estações de tratamento localizadas a jusante dos reservatórios e dos investimentos necessários em tecnologia de tratamento de água que só têm expressão quando observados pelas conexões dessa imensa rede de infraestrutura hídrica (PIRES DO RIO, 2006).

Os condicionantes dessa rede estendem-se, portanto, para além de uma unidade espacial estável. A escala da gestão foi condicionada pela competência atribuída respectivamente às duas empresas (Light e CEDAE), com predomínio da companhia de eletricidade no controle da afluência da água. Uma constatação se impõe: esse tipo de rede de infraestrutura contém um grau elevado de tecnicidade cuja topologia responde às exigências de funcionalidade e eficiência dos serviços a que estão associados. Por outro lado, a gestão, a cargo quase exclusivo dessas companhias, apresenta impasses em termos de legitimidade no próprio processo de gestão. Consideradas as malhas de gestão e as redes infraestrutura, a base natural instituída perde muito do seu sentido, pois tais malhas resultam da confrontação entre a lógica técnica das redes de infraestrutura, a lógica de diferentes atores e da lógica de políticas públicas.

A partir dos elementos mencionados, podemos considerar que em tais superfícies mesclam-se as ações de agentes que são bastante regulados, como as companhias de eletricidade e de saneamento. Ao mesmo tempo, a atuação setorial dificulta uma compreensão mais ampla do processo de gestão. Em áreas de incidência de população indígena, as peculiaridades de sua relação com a água e os direitos de uso fogem à lógica da complexa regulação econômica que incide sobre as organizações públicas e privadas. Nos espaços assim regulados há também um jogo de escalas que assegura o direito de acesso ao serviço e a um elemento essencial à vida, portanto, continuidade e universalidade dos serviços pressupõem funcionamento técnico e condições objetivas de coesão institucional em bases territoriais distintas.

\section{À GUISA DE CONCLUSÃO}

O propósito deste trabalho foi discutir, à luz dos aportes da perspectiva institucionalista aplicada à geografia, as interações entre regulação e território. Do exposto, identificou-se que as relações entre território e regulação implicam em considerar crescentes polarizações entre público e privado e entre escalas global, regional e local. Essas polarizações são acentuadas por um modelo escalar segmentado, no qual a escala regional é compreendida como unidade espacial de fraca capacidade regulatória, principalmente em contextos econômicos e políticos que tendem a negligenciá-la. Por outro lado, concepções teóricas que privilegiam a articulação entre escalas e consideram a esfera regional como escala de manifestação de coesão institucional podem ser consideradas essenciais para a renovação da geografia econômica: a trajetória das regiões depende em grande medida do aparato, arranjo, ambiente, densidade e coesão institucionais.

Nesta perspectiva, tratar a relação entre território e regulação requer temporalidades e espaços diferentes daqueles que estamos acostumados a levar em 
conta em nossos trabalhos. Ao longo da discussão apresentada, defrontamo-nos com as noções de dominialidade, patrimônio e conflito federativo que mostram o quanto a complexidade das malhas de gestão não permite a redução a uma unidade espacial imutável. Ao considerarmos as redes de infraestrutura, aspectos relevantes puderam ser evidenciados, tais como: a interdependência e a lógica de redistribuição e acessos a recursos essenciais como a água. Os elementos de confrontação entre recursos compartilhados e espaços políticos constituídos a partir das redes de infraestrutura são objeto de escolhas coletivas.

Confrontando-se as redes técnicas às malhas de gestão, observou-se que as superfícies de regulação são conceitualmente adequadas para apreender as questões relativas ao acesso aos recursos. Não se trata de reforçar as ideias bastante desgastadas, porém não esgotadas, de redução das disparidades regionais, e sim compreender que uma possível equidade de acesso remete a contradições que, em sua duração, tendem a criar novas territorialidades. Por fim, a partir dos dois exemplos que ilustram a diversidade de situações em termos de acesso à água, indicou-se a complexidade e imbricação territorial que propiciam os sistemas regulatórios.

A perspectiva institucional abre um campo de reflexão importante. Consideramos como principal contribuição a possibilidade de descrição e análise do espaço econômico. Várias pistas de investigação podem ser identificadas e trilhadas, dentre as quais destacamos o estudo dos dispositivos regulatórios e suas implicações nas práticas de gestão. A noção de superfície de regulação é apenas uma das possibilidades que vimos explorando na tentativa de explicar a complexidade das relações econômicas e sociais bem como os limites da tese de uma naturalização fundadora de territórios. 


\section{NOTAS}

1 - Este trabalho é uma versão revisada e atualizada daquele apresentado nos Anais do VII Encontro da Associação Nacional dos Programas de Pós-Graduação em Geografia. Foram incorporados alguns parágrafos do capítulo "Território, instituições e superfície de regulação", da coletânea Questões metodológicas e Novas Temáticas na Pesquisa Geográfica PPGG/UFRJ, 2009. Agradeço a gentileza e o interesse da Tamoios em recuperar o artigo.

2 - Lembramos que os serviços de água e esgoto, de responsabilidade dos municípios, foram objeto de privatização e apresentam balanço pouco conclusivo a respeito de sua eficiência em termos de universalização (PIRES DO RIO; SALES, 2004). A titularidade dos serviços tem sido um permanente motivo de conflitos e disputas.

3 - Na atualidade, mares e oceanos constituem objeto de disputas e também de forte regulação pela raridade de marcos físicos e pela mobilidade dos recursos vivos, de tal modo que os tratados e convenções que projetam malhas em superfície (zonas econômicas exclusivas) e em coluna (solo, subsolo e espaço aéreo marítimo) engendram um processo de territorialização do espaço marinho.

4 - As redes de infraestrutura podem ser consideradas serviços públicos, na tradição francesa, ou serviço universal na tradição inglesa, no entanto, tal universalidade é difícil de ser de fato observada (OFFNER, 2000).

5 - As indústrias em rede compreendem quatro setores: comunicação, energia, transporte e saneamento. Enquanto as três primeiras são constituídas inicialmente em escala local e, progressivamente, passaram a operar em escala nacional, o saneamento permaneceu organizado em escala regional e local.

6 - A não exclusividade refere-se admissão de usuários mesmo que estes não contribuam ao financiamento, enquanto a não-rivalidade diz respeito à possibilidade de consumo simultâneo por várias pessoas. A dimensão da rede de infraestrutura pode, no entanto, limitar o acesso de parte da população ao serviço, mas esse fato não elimina os princípios que caracterizam tais serviços (LEVÊQUE, 1998).

7 - Uma das primeiras empresas de água na Inglaterra, a New River, atual Thames Water, construiu, em 1613, um sistema de captação e reservatórios para a cidade de Londres. Parte desse sistema ainda está em operação.

8 - Multiutilities são companhias que operam redes de infraestrutura.

9 - Sintomaticamente, essas estações de transferência são denominadas city gates.

10 - A evolução do mapa da telefonia ilustra claramente os monopólios regionais formados desde o processo de privatização em 1998, assim como o mapa das distribuidoras de energia elétrica.

11 - O termo instrumentalização é aqui empregado para indicar uma forma de controle dos recursos que asseguram uma atividade. Não é mais suficiente controlar a fonte em si, mas a região natural, que dotada e conectada por redes técnicas, confere estabilidade indissociável ao serviço.

12 - A governança está, pois, associada à ação de atores coletivos.

13 - Não obstante o trabalho de Dicken (1992), que nos inspirou na aplicação deste conceito à realidade brasileira (PIRES DO RIO; PEIXOTO, 2001), focar mais diretamente as diferenças de regulação entre países, podemos traçar alguns paralelos entre as superfícies de regulação consideradas em macro-escala e aquelas que correspondem a escalas intermediárias.

14 - A esse respeito, cabe lembrar o trabalho de Sassen (2006, op. cit.) que considera que o processo de globalização intervém menos nas fronteiras do território nacional do que em sua adaptação institucional.

15 - A noção de patrimônio natural deve ser objeto problematização na medida em que implica considerar o natural como categoria passível de apropriação e transmissão como em regime privado.

16 - Secretaria de assessoria direta da Presidência da República e, portanto, não submetida às agências setoriais como a ANA e a ANEEL. 
17 - Os recentes leilões para exploração de blocos de petróleo ou para a exploração de rodovias ilustram o regime de cessão onerosa, que prevê o pagamento pelo direito de explorar determinado recurso ou serviço.

18 - Dentre as atribuições da SEAP destaca-se: assessorar a formulação de políticas e diretrizes para a produção pesqueira e aquícola, normatizar e estabelecer medidas para o aproveitamento de recursos pesqueiros e manter programas de aquicultura em águas públicas e privadas.

19 - Áreas individuais podem ser requeridas. Interferem na reserva de áreas para obtenção do direito de cessão o IBAMA (licença ambiental), a ANA (para avaliar a capacidade de suporte) e em alguns casos a Marinha (trânsito para embarcações).

20 - Dez anos após, algumas informações não estão mais disponíveis nos sítios consultados àquela ocasião. É de fato um ponto que merece ser avaliado com cuidado.

\section{REFERÊNCIAS BIBLIOGRÁFICAS}

AMIN, A. "Una perspectiva institucionalista sobre el desarollo econômico". Cadernos do IPPUR, Rio de Janeiro ano XIV (2), 2000. 47-68.

AMIN, A; THRIFT, N. Globalization, Institutions and Regional development in Europe. Oxford: Oxford University Press, 1994.

AOKI, M. Horizontal vs vertical information of structure of the firm. American Economic Review 76 (5), 1986.

BENKO, G. Economia, Espaço e Globalização na aurora do século XXI. São Paulo HUCITEC, 1996.

BENKO, G; LIPIETZ, A. La richesse des Régions : la nouvelle géographie socioéconomique. Paris: PUF., 2000.

BOYER, R. "Les problématiques de la régulation face aux specificités sectorielles". Chaiers d'économie et sociologie rurales (17): 40-93, 1990a.

BOYER, R. A teoria da regulação: uma análise crítica. São Paulo: Nobel, 1990b.

BOYER, R.; SAILLARD (org) Théorie de la régulation: l'état des savoirs. Paris: La Découverte, 1995.

CLARK, G et al.. The Handbook of Economic Geography. Oxford: Oxford University Press, 2000.

COREI, T. L'économie institutionnaliste. Paris: Economica, 1995.

CUMBERS, A, et al. "Institutions, Power and Space: Assessing the limits to institutionalism in Economic Geography" European Urban and Regional Studies 10(4): 325-342, 2003.

DICKEN, P. "International production in a volatile regulatory environment: the influence of national regulatory policies on the spatial strategies of transnational corporations" Geoforum 23 (3): 303-316, 1992.

DUPUY, G. L'urbanisme des réseaux: théories et méthodes. Paris: Armand Colin, 1991.

HUDSON, R. Economics Geographies, London: SAGE Publications Ltda, 2005. 
GILLY, J-P; PECQUEUR, B. "La dimension locale de régulation” In: BOYER, R.; SAILLARD. Théorie de la régulation: l'état des savoirs. Paris: La Découverte, 1995.

JACOBI, P. Governança da Água no Brasil. In: RIBEIRO, W C Governança da água no Brasil: uma visão interdisciplinar. São Paulo AnnaBlume, 2009.

JESSOP, B. "The regulation approach, governance and post-fordism: alternative perspectives on economic and political change?" Economy and Society 24, 307-333, 1995.

JESSOP, B. "Institutional re(turns) and the strategic-relational approach". Environment and Planning A 33 (7): 1213-1235, 2001.

KNIGHT, J. Institutional and social conflict. Cambridge: Cambridge University Press, 1992.

LACOSTE, Y. Géopolitique de l'eau. Hérodote. (102), $2001 \mathrm{a}$.

LACOSTE, Y. L'Eau des hommes. Paris Cercle d'Art, 2001b.

LÉVÊQUE, F. Économie de la réglementation. Paris: La Découverte, 1998.

LÉVY, J; LUSSAULT, M (dir.) Dictionnaire de la Gégraphie et de l'espace des sociétés. Paris: Berlin, 2003.

MARTIN, R. "Institutional Approches in Economic Geography". In SHEPPARD, E e BARNES, T A companion to Economic Geography (eds.). Oxford: Blackwell, 2000.

MUSSO, P; CROZET, Y,; JOIGNAUX, G. (Dir.) Le territoire aménagé par lês réseaux. Paris: Éditions de leeaube/Datar, 2002.

NORTH, D. Institutions, Institutional Change and Economic Performance. Cambridge: Cambridge University Press, 1990.

OFFNER J. M.: Territorial Deregulation: local authorithies at risk from technical networks International Journal of Urban and Regional Research 24 (1). 2000. 165-182.

OFFNER J.-M.; PUMAIN D. (dir.): Réseaux et territoires, significations croisées, Editions de lecAube, 1996.

PECK, J: "Doing Regulation". In CLARK, G. L, MARYANN, P. F. e GERTLER, M.(eds.) The Oxford Handbook of Economic Geography. Oxford: Oxford University Press, 2000.

PERROUX, F. Pouvoir et économie généralisée. Grenoble: Presses Universitaires de Grenoble [1973] 1994.

PERROUX, F. L'économie au XXe siècle. Grenoble: Presses Universitaires de Grenoble, 1961.

PIRES DO RIO, G A. "Recursos Hídricos e Território: tensões e cooperação". Anais do III Encontro da Associação Nacional de Pesquisa e Pós-Graduação em Ambiente e Sociedade. Brasília, DF, 2006.

PIRES DO RIO, G A. “Gestão de Águas: um desafio geoinstitucional”. In OLIVEIRA, M P et AL (org): O Brasil, a América Latina e o Mundo: espacialidades contemporâneas. Vol 1. Rio de Janeiro: Lamparina: ANPEGE, 2008.

PIRES DO RIO, G A; PEIXOTO, M N de O. "Superfície de regulação e conflitos de atribuições na gestão de recursos hídricos". Território (10), 2001. 51-65. 
PIRES DO RIO, G A; PEIXOTO, M N de O; MOURA, V P. Lei das Águas: desdobramentos para a gestão ambiental e territorial. In: MATA, S F et al. Educação Ambiental: Projetivas do Século. Rio de Janeiro: MZ Editora, 2001. p 93-99.

PIRES DO RIO, G A; SALES, A V S. Os serviços de água e esgoto no Estado do Rio de Janeiro: regulação e privatização. GEOgraphia VI N 12, 2004. 67-86.

RAFFESTIN, C. Pour une gégraphie du pouvoir. Paris: Librairies Techniques, 1980.

SASSEN, S. Territory, Authority Rights: from medieval to global assemblages. New Jersey: Princeton University Press, 2006.

SCOTT, R W. Institutions and organizations. Londres: Sage, 1995.

SILVA, R T. "Infraestrutura socioeconômica do estado de São Paulo e a dinâmica urbano-regional recente. Interações entre a organização da oferta de infraestrutura no Brasil e as relações entre o público e o privado na gestão urbana e regional". In: GONÇALVES, M.F.; BRANDÃO, C.A.; GALVÃO, A.C.F. (orgs). Regiões e cidades, cidades nas regiões: o desafio urbano-regional. São Paulo : Editora UNESP-ANPUR, 2003.

STORPER, M. The Regional World: territorial development in global economy. New York: Guilford, 1997..

SWYNGEDOUW, E. A Cidade como um Híbrido. In: Acselrad, H. (org.) A Duração das Cidades. Rio de Janeiro. DP\&A. 2001.

THRIFT, N.; OLDS, K. "Refiguring the Economic in Economic Geography"e, Progress in Human Geography 20, 1996, 311-27.

WILlIAMSON, O. E. The Economic Institutions of Capitalism: Firms, Markets, Relational Contracting. New York: Free Press, 1985.

WOOD, A.; VALLER, D. „Turn Again? Rethinking Institutions and the Governance of Local and Regional Economies ${ }^{e e}$, Environment and Planning A, 2001. 33: 1139-44. 